\title{
El duelo por honor como práctica identitaria, colonial y excluyente en la Argentina moderna *
}

\author{
The duel for honor as an identity, colonial and exclusionary practice in \\ modern Argentina.
}

Por: Paradela, Juan Ariel ${ }^{*}$

Universidad de Buenos Aires UBA-FFyL

CABA, Argentina

Correo electrónico: jparadelafilo@gmail.com

Fecha de recepción: 1/03/2021

Fecha de aprobación: 31/05/2021

DOI: http://dx.doi.org/10.30972/nvt.1715358

\section{Resumen}

A la luz de los múltiples y equívocos usos de la noción de honor en la actualidad argentina y latinoamericana, es posible desconcertarse ante la aparición de tal concepto. En este trabajo se comenzará situando el concepto de honor tradicional desde la perspectiva filosófica hegeliana y comprendiendo el lugar que este ocupa en su teoría del reconocimiento. Luego, se pretenderá analizar cómo el concepto de honor, entendido como un englobador de valores propios de un mundo, cae para dar lugar al mundo de la dignidad, siguiendo el trabajo de Berger (1983).

Estos dos momentos desembocarán en el análisis de como las élites porteñas reciben y ponen en práctica este concepto en el período de conformación de la Argentina moderna (Gayol, 2008). De este modo, se pretende dar respuesta a por qué la noción de honor en las élites porteñas constituía un elemento clave en la identificación y reconocimiento propio. A su vez, el honor traza en dicho contexto un

\footnotetext{
* En este trabajo se expresan los avances de mi proyecto de investigación en el marco de una adscripción, dirigida por la Prof. Bárbara Aguer, en la cátedra de Filosofía de la Cultura de la Universidad de Buenos Aires. Además, este escrito está vinculado al proyecto UBACyT del cual formo parte: "Cultura (s) y ciudadanía (s). Aproximación ético-político intercultural a las nuevas formas de inclusión y exclusión en / de los derechos humanos", dirigido por la Dra. Alcira Beatriz Bonilla.

* Estudiante avanzado de la licenciatura en Filosofía de la Universidad de Buenos Aires y adscripto a la cátedra de Filosofía de la Cultura de dicha Universidad. Integrante del Centro de Formación y Pensamiento Génera.
} 
límite demarcatorio con los varones de las clases populares, en un momento histórico en donde la ciudadanía (que implicaba la garantía de los derechos liberales) se encontraba en plena ampliación. Estos últimos, según las elites, no defendían el honor en sus duelos, sino que más bien sus disputas "por honor" eran prácticas violentas y bárbaras. Esta práctica de exclusión racial se pretenderá comprender mediante el análisis de la idea de raza desarrollada por Aníbal Quijano, especialmente en Colonialidad del poder, eurocentrismo y América Latina (2000).

Palabras clave: noción de honor, construcción identitaria, exclusión social y racial, teoría del reconocimiento, Hegel.

\section{Abstract}

In the light of the multiple and equivocal uses of honor in Argentina and Latin America at the present time, it is possible to be puzzled by the appearance of such concept. This paper will begin by situating the concept of traditional honor from the Hegelian philosophical perspective and understanding the place it occupies in his theory of recognition. Then, we will analyze how the concept of honor, considered as an encompassing of values proper to a world, falls to give place to the world of dignity, following Berger (1983).

These two moments will lead to the analysis of how the Argentine elites receive and put into practice this concept in the period of conformation of modern Argentina (Gayol, 2008). In this way, it is intended to answer why the notion of honor in the Argentina elites constituted a key element in self-identification and self-recognition. Furthermore, in this context, honor traces a demarcation boundary with the men of the popular classes, in a historical moment when citizenship (which implied the guarantee of liberal rights) was in full expansion. The latter, according to the elites, did not defend honor in their duels, but rather their disputes "for honor" were violent and barbaric practices. This practice of racial and social exclusion will be understood 
El duelo por honor como práctica identitaria, colonial y excluyente en la Argentina moderna

through the analysis of the idea of race developed by Aníbal Quijano, especially in Coloniality of Power, Eurocentrism and Latin America (2000).

Keywords: notion of honor, identity construction, social and racial exclusion, recognition theory, Hegel.

\section{Cómo citar este artículo:}

APA: Paradela, J. A. (2021). El duelo por honor como práctica identitaria, colonial y excluyente en la Argentina moderna. Nuevo Itinerario, 17 (1), 284-309. Recuperado de: (agregar dirección web)

\section{Introducción}

Una mujer inventó una cuenta de Twitter y desde allí denunció a un hombre por haber cometido una serie de delitos. Las acusaciones se viralizaron y el apuntado sintió que eso afectaba su nombre y su honor. La historia podría haber terminado en un par de tuits y pasado al olvido. Sin embargo, la víctima fue a la Justicia y al cabo de un año convirtió su caso en el primer precedente judicial sobre el que habrá que estar alerta: publicar en redes sociales una incriminación falsa puede terminar en una condena. (Soriano, 2018)

Como demuestra este extracto de una noticia reciente, en la vida cotidiana, como en ámbitos más específicos, el concepto de honor es un concepto vivo, presente y en disputa. Será objeto de este trabajo, en primer lugar, analizar cómo este concepto es parte de la teoría de reconocimiento que Hegel desarrolla en EI sistema de la eticidad (2006), el cual se inscribe en su período de Jena.

En una segunda instancia, se analizarán las proposiciones realizadas por Berger acerca del lugar que ocupa el honor en la sociedad. Se mostrará en detalle el 
movimiento y la justificación que el autor otorga al concepto de honor, con la caída del antiguo régimen, por la idea de dignidad.

En tercer lugar, a partir de los aportes realizados en el ámbito argentino por Sandra Gayol, se intentará analizar cómo fue la recepción y el uso del concepto de honor y de la práctica del duelo, enfatizando el rol que cumplieron para con la conformación de la Argentina moderna. En este sentido, pretenderé dar respuesta a por qué la noción de honor en las élites porteñas constituía un elemento clave en la identificación y reconocimiento de ellas mismas, y un límite demarcatorio con los varones de las clases populares en un momento histórico en donde la ciudadanía (que implicaba la garantía de los derechos liberales) se encontraba en plena ampliación.

Con estos tres momentos, el trabajo apunta a mostrar el pasaje de una noción de honor aristocrático a una noción de honor republicano a partir de los desplazamientos que es posible observar en los estudios de Berger, centrados en la experiencia de Europa occidental en el contexto de caída del ancien regime y el estudio de Gayol, en los tiempos de la conformación de la Argentina moderna. Precisamente el honor republicano, bajo la práctica del duelo en las élites argentinas, se puede considerar como una técnica de blanqueamiento $y$ occidentalización de este sector social. En este sentido, creo advertir que la persistencia de una gramática del honor en nuestras sociedades durante el siglo XIX parecería explicarse por la misma colonialidad del poder (Quijano 2000).

\section{La teoría de reconocimiento hegeliana en El sistema de la eticidad}

Es preciso comenzar el análisis del texto a tratar -El sistema de la eticidad (2006)-, escrito en el período de Jena (comprendido entre 1803-1807), haciendo una breve mención a distintos procesos y teorizaciones que nos llevan al desarrollo hegeliano. En este sentido, desde la política clásica de Aristóteles hasta la del derecho natural 
El duelo por honor como práctica identitaria, colonial y excluyente en la Argentina moderna

cristiano en la Edad Media, el hombre había sido concebido esencialmente como un ser comunitario (zoon politikon), de manera que la realización verdadera de su naturaleza solo se podía producir en el marco de una comunidad ética, que es aquella caracterizada por la importancia de ciertas virtudes intersubjetivas.

Luego, en el período que comienza en la baja Edad Media y que culmina en el Renacimiento, sucedió que junto con la introducción de nuevos modos de comercio y por la autonomización de los principados (italianos), aconteció un proceso económicopolítico que había desbordado los cauces protectores de las costumbres tradicionales (Honneth, 1997, p.16). Así, en la teorización de estas nuevas condiciones, Maquiavelo se desprendía de las premisas antropológicas que habían caracterizado a la tradición filosófica e introducía al hombre como un ente egocéntrico, solo ocupado en su propio interés. De esta manera, según Honneth, es que, 120 años después, Hobbes le da una hipótesis científica a la convicción fundamental de Maquiavelo. Hobbes, a raíz de las experiencias histórico-políticas de la constitución de un moderno aparato de Estado y de una aún mayor circulación de mercancías, junto con el método de las ciencias de la naturaleza, ya usado por Descartes y Galileo, describe la condición natural del hombre, comenzando por marcar que tiene derecho natural a todo, incluso al cuerpo de los demás y que al estar en una condición de guerra de todo hombre contra todo hombre, "no hay lugar para la industria; porque el fruto de la misma es inseguro". (Hobbes, 2007, p.130). Es en esta situación, donde la vida es miserable y solitaria, y donde tampoco hay espacio para las nociones de justicia e injusticia, donde Hobbes muestra que a la base del vivir juntos está el miedo a la muerte violenta y el cálculo egoísta de los individuos.

Ahora bien, hay que entender la teoría del reconocimiento hegeliana enmarcada en una crítica a la teoría política hobbesiana por su carácter individualista. Específicamente, criticará que la teoría de Hobbes es incapaz de dar cuenta de la vida social y de las relaciones comunitarias. La posición que Hegel es que hay una demanda precontractual de reconocimiento, necesaria para la posterior predisposición de los individuos a delimitar la esfera de la libertad. 


\section{Juan Ariel Paradela}

En El sistema de la eticidad (2006), Hegel mostrará la transición de la eticidad natural a la totalidad ética. Un presupuesto que Hegel introduce es el que recoge de la ontología aristotélica, esto es, que este proceso de ampliación debe tener la forma de uno teleológico, donde una "sustancia originaria" consigue paso a paso su desarrollo. Allí encontraremos, como se explicará, que es la existencia de la diferencia lo que saca la eticidad de su estadio natural y lo conduce finalmente a la unidad de lo general y de lo particular. En este texto, Hegel muestra tres fases significativas que nos llevan a la unidad entre el individuo y la sociedad. En primer lugar, nos encontramos con la eticidad natural. Aquí establece dos relaciones de reconocimiento recíproco. Previo a describir estas dos relaciones, Hegel presenta a los hombres como aquellos que buscan "en las cosas de la naturaleza la satisfacción de aquello que les permite vivir" (Prada, 2015, p.30). Aquí el hombre no es capaz de distinguirse de la naturaleza, ya que su trabajo, frente a estos objetos exteriores, es mecánico, pues la individualidad se encuentra bajo la forma de la indiferencia (Hegel, 2006, p.116). Sin embargo, el hombre pronto se percata que las cosas del mundo se le oponen, que resisten a él al ser realmente objetivas, lo que lleva a que este tenga la necesidad de poseerlas y de exigir que las cosas le otorguen, al mismo tiempo, la satisfacción inmediata de sus necesidades. Pero esto no ocurre, por lo tanto, el hombre encuentra que "existe una necesidad que no puede ser satisfecha con cosas, sino con la presencia de personas. Se trata, dice Hegel, de la necesidad de afecto, que se satisface mediante relaciones de amor" (Prada, 2015, p.30). Aquí nos encontramos con la primera relación de reconocimiento, donde hay dos amantes que se constituyen en una unidad, aunque dentro de una negatividad, la cual es superada, según Hegel, con la procreación de un hijo.

A esta forma de reconocimiento le sigue aquella que debe resolver los conflictos surgidos en las relaciones de propiedades contractualmente reguladas. La diferencia esencial respecto de la primera forma de reconocimiento es que aquí "las referencias prácticas que los individuos ya en el primer estadio mantenían respecto al mundo, se desgajan de sus condiciones de validez simplemente particulares, y se transforman en exigencias jurídicas generales y fundadas en contrato" (Honneth, 1997, 
El duelo por honor como práctica identitaria, colonial y excluyente en la Argentina moderna

p.30). De manera que ahora los sujetos deben ser vistos como propietarios, refiriéndose los unos a los otros como personas, ya que todos ellos están bajo el ala del derecho formal. Hay que tener en cuenta que el conflicto, que se puede caracterizar como la negación de reconocimiento formal del otro, se genera sobre la base de una diferencia del poder vital, es decir, por la existencia de relaciones de dominación y servidumbre entre las personas. Por lo tanto, lo que el derecho debe garantizar es el reconocimiento de todo individuo como sujeto de derecho. En esta transición que posibilita el derecho lo que ocurre es que hay una aniquilación de lo singular de cada sujeto, ya que "los contratantes son aniquilados en cuanto individuos, y [un espíritu] constituye lo universal concreto que subsume a los contratantes" (Hegel, 2006, p.133).

Por otro lado, el ser sujeto de derecho implica que la persona pueda ser reconocida como libre de poseer diversas cosas particulares, de este modo siendo reconocida por los otros como poseedor y como sujeto de derecho. En síntesis, en esta instancia nos encontramos con el reconocimiento afectivo y el del derecho, que implica ser reconocido, respectivamente, como individuo en el amor, y como persona en las relaciones de derecho.

Ahora bien, en segunda instancia nos encontramos con el delito. Lo que sucede es que mediante el robo y el despojo, se rompe la relación de propiedad establecida por el derecho y, simultáneamente, acontece la negación de la persona, la cual se experimenta como una ofensa al honor (Prada, 2015, p.33). Así, con el robo, se ve amenazada la persona en su identidad. Cuando Hegel comenta que la "determineidad" del individuo es herida, lo que se está hiriendo es el honor, entendido aquí como aquello propio del individuo, en tanto que lo diferencia de ser un mero sujeto de derecho (Hegel, 2006, p.149). De forma que la lesión del honor, en esta instancia, instaura una lucha para recuperar aquello sustraído o lesionado. Como comenta Prada, "no solo se rompe la relación entre la persona y la cosa robada, sino también entre quien roba y quien ha sido robado" (Prada, 2015, p.33). Esto produce un enfrentamiento donde el agredido, al haberse sentido lesionado en su honor, en su totalidad en cuanto persona, se siente como poseedor y sujeto libre (Prada, 2015, 


\section{Juan Ariel Paradela}

p.34). Entonces, solo el sujeto lesionado lucha por la integridad de su persona como un todo, ya que el delincuente solo estaría movido por un interés particular (Honneth, 1997, p.34).

Aquí encontramos una diferencia con la lucha de todos contra todos hobbesiana, ya que el significado que prima aquí es la lucha por la autoafirmación como persona o esencia libre y no la lucha por la supervivencia. Mientras el honor en Hobbes remite a la necesidad de afirmación del poder propio ante los otros, en conjunto con la necesidad de asegurar el respeto de la vida propia, el honor para Hegel es "la conciencia y el saber que tiene el sujeto de sus determinaciones o particularidades" (Rendón, 2010, p.76). Por eso mismo, la lucha por el honor es una lucha a muerte por la propia libertad, que se da entre sujetos que se reconocen a sí y a los otros como igualmente libres. Específicamente, para Honneth, el honor en Hegel consiste en "la posición que adopto frente a mí mismo cuando identifico positivamente mis cualidades y mi especificidad" (1997, p.35). De modo que solo por un combate por el honor un individuo adquiere plena identificación consigo mismo. Así Honneth concluye que "con el 'honor' se distingue, pues, una relación afirmativa consigo mismo que estructuralmente está ligada al presupuesto del reconocimiento intersubjetivo de la particularidad individual" (Honneth, 1997, p.35).

Cabe resaltar, como lo hace Abril en su lectura del texto de Honneth, que la motivación del que comete el delito, en primera instancia, "es una falta de reconocimiento de su singularidad y de su lugar en la comunidad que se pasa por alto en las relaciones ético-jurídicas" (Abril, 2012, p.12). Es este estado de reconocimiento incompleto lo que, según Honneth, motiva al delincuente hegeliano ${ }^{1}$. A raíz del delito, se da lugar a la instancia de la eticidad absoluta. De modo que a los actos delictivos, además de otorgarles la característica de negación, se los debe entender como una instancia de construcción en tanto genera una formación de conciencia. Aquí podemos

\footnotetext{
${ }^{1}$ Es preciso preguntarse aquí qué lugar deja esta perspectiva de la teoría del reconocimiento para aquel desposeído, que no tiene propiedad y que es motivado a robar. En este sentido, si Hegel plantea que el que roba tiene un reconocimiento incompleto, una teoría del reconocimiento descolonial debería abordar esta situación y analizar cómo es posible la construcción y reconocimiento de sí mismo.
} 
El duelo por honor como práctica identitaria, colonial y excluyente en la Argentina moderna

encontrar un paso de la persona formal, como un individuo que es reconocido intersubjetivamente al ser un sujeto de derecho, a la persona como un todo, que es aquel individuo que ha logrado un reconocimiento intersubjetivo de sí mismo como poseedor de sus particularidades.

Luego del delito nos encontramos con la tercera fase, la cual podemos caracterizar como el momento donde se conforma la integración social. Aquí Hegel entiende que luego del delito los sujetos logran una conciencia acerca de su recíproca dependencia. De modo que así puede entenderse que los individuos se conciban como miembros de un todo ${ }^{2}$, logrando la deseada unidad. En esta comunidad moral o totalidad ética encontramos que "los seres humanos se reconocen entre sí al compartir costumbres, tradiciones y prácticas" (Prada, 2015, p.35) de manera que constituyen un pueblo. Aquí las diversas instituciones, como el Estado, sirven para la realización de los fines particulares que se definen unívocamente por ser intrínsecamente intersubjetivos e identificables con los fines del pueblo, ya que este constituye "el lugar de afirmación del individuo qua individuo que reconoce su pertenencia a un Todo" (Prada, 2015, p.36).

En esta instancia es donde Siep, según De La Maza (2010), encuentra que hay una asimetría característica de la relación de los individuos con el Estado, ya que estos no son tomados por el Estado por medio de sus determinaciones particulares únicas e irrepetibles. Lo que Siep afirma es que el Estado toma a los individuos en su "singularidad", esto es, como sujetos que han superado sus determinaciones particulares, cosa que se refleja en tanto que estos se identifican "con las costumbres, leyes e instituciones de la comunidad" (De La Maza, 2010, p.74).

\section{Tensiones y redefiniciones del concepto de honor}

\footnotetext{
2 Hegel habla además de que el individuo se intuye a sí mismo en cada uno, intentando así designar en esta instancia "una forma reflexiva de relaciones recíprocas entre sujetos" (Honneth, 1997, p.37).
} 
Habiendo ubicado el honor en la teoría de reconocimiento de Hegel y caracterizándolo como aquel saber y posición que un sujeto tiene de sus particularidades, es preciso en este apartado presentar el análisis que Peter Berger elabora en Sobre la obsolescencia del concepto de honor (1983) para pensar al honor dentro de los esquemas de reconocimiento actuales.

El sociólogo afirma que el concepto de honor ha sido reemplazado en la modernidad por el concepto de dignidad y que han surgido como contrapartida nuevas moralidades en conjunto con un renovado humanismo y una preocupación por los derechos del individuo. Como lo expresa el autor "the same modern men who fail to understand an issue of honor are immediately disposed to concede the demands for dignity and for equal rights" [los mismos hombres modernos que fallan en comprender una cuestión de honor están inmediatamente dispuestos a conceder las demandas de dignidad y de igualdad de derechos] (Berger, 1983, p.172).

Ahora bien, el autor entiende que el honor es un concepto que evoca una distinción aristocrática donde se apela a una división de orden jerárquica en una sociedad. Además de resaltar la influencia de los códigos medievales de la caballería para con la definición de este concepto, también entiende que este ha prevalecido en la modernidad en grupos atravesados por una mirada jerárquica de la sociedad, como en los militares o en las tradicionales profesiones burguesas (abogacía y medicina), donde el honor es la expresión directa del estatus social. En esta sintonía, el honor implicaría la puesta en práctica de ciertos estándares de comportamiento. Sin embargo, el autor nos hace pasar a otra faceta del honor al situarlo, basándose en el estudio de Campbell ${ }^{3}$ acerca de la cultura rural contemporánea en Grecia, como un concepto que atraviesa a la sociedad en su totalidad, en tanto cada sujeto forma parte de un sistema único pero diferenciado de honor.

Ahora bien, el autor comprende que este concepto se desintegra bajo el impacto de la modernidad. El proceso que expresa como punto de partida es el aburguesamiento del honor, el cual toma lugar dentro del proceso, definido por

\footnotetext{
${ }^{3}$ Véase el estudio de Campbell (1964): Honour, Family and Patronage.
} 
El duelo por honor como práctica identitaria, colonial y excluyente en la Argentina moderna

Norbert Elias, de "civilización"4 ${ }^{4}$ El sociólogo comenta que allí, en la conciencia de los intelectuales críticos, se desacredita el concepto de honor del antiguo régimen y los prototipos jerárquicos que concebían. Además, estos concebían que la nueva sociedad que emergía liquidaría cualquier concepción del honor. Esto último Berger lo ejemplifica al mostrar que El Quijote, Cervantes expresa la obsolescencia del concepto de honor en tanto presenta a un caballero errante en una época donde la caballería se ha convertido en una retórica vacía. De manera que el libro expresa no solo la "locura" de la caballería misma, sino también el absurdo de identificarse con estas arquetípicas formas de comportamiento. Esto Berger lo encuentra sintetizado en lo que Don Quijote le dice a Sancho: “¿Qué es posible que en cuanto andas conmigo no has echado de ver que todas las cosas de los caballeros andantes parecen quimeras, necedades y desatinos, y que son todas hechas al revés?" (Cervantes, 1922, p.121). De modo que nos hace entender que todo sujeto que pretenda identificarse o dotarse de honor se encontrará en la ilusión y la locura.

En contraste con el honor, el concepto y la percepción de la dignidad pertenece a todo individuo, ya que trasciende cualquier posición que este ocupe en la sociedad. Esta característica esencial de la dignidad el sociólogo lo ve expresado en la declaración universal de los derechos humanos de las Naciones Unidas, donde se expresa la existencia de derechos que pertenecen a todos los individuos independientemente de su raza, color, credo, sexo y edad. Como afirma el autor, tanto el honor como la dignidad se expresan en la relación con los otros, en tanto pueden ser sostenidas o amenazadas por la comunidad. Y como ambas requieren un esfuerzo de la voluntad para su mantenimiento (Berger, 1983, p.176), se vuelven entonces objetivos específicos de diversas iniciativas morales.

La diferencia esencial que Berger traza entre estos dos conceptos refiere a pensar que el concepto de honor implica que la identidad está esencialmente vinculada a los roles institucionales, mientras que el concepto moderno de dignidad implica que la identidad es independiente de los roles institucionales. De manera que,

\footnotetext{
${ }^{4}$ Para mayores precisiones, véase el libro de Norbert Elias (1993): La sociedad cortesana.
} 
mientras en un mundo de honor el individuo se identifica con símbolos sociales como su escudo, en un mundo de dignidad la simbología social es un disfraz, ya que los escudos ocultan al verdadero yo (Berger, 1983, p.177). Por eso entendemos que en el mundo de honor el individuo descubre su identidad en los roles, mientras que en un mundo de dignidad el individuo solo puede descubrir su verdadera identidad emancipándose, liberándose de los roles sociales impuestos.

También Berger menciona una diferencia en el modo de comprensión de la historia. Mientras que en el mundo del honor la identidad se vincula al pasado mediante la práctica reiterada de actos prototípicos; en el mundo de la dignidad, por el contrario, la historia es la sucesión de mistificaciones de la cual el individuo debe liberarse para lograr su autenticidad.

Por último, quisiera señalar que Berger enfatiza que el rol de las instituciones fue la de crear sentido y estabilidad al individuo, pero que ahora, en el mundo de la dignidad, se ven fragmentadas y así privadas de plausibilidad. Como enfatiza el sociólogo, "the individual is thrown back upon himself, on his own subjectivity, from which he must dredge up the meaning and the stability that he requires to exist" [el individuo es arrojado sobre sí mismo, sobre su propia subjetividad, desde la que debe extraer el sentido y la estabilidad que requiere para existir] (Berger, 1983, p.178). Es esta situación la que el autor establece como base necesaria para la aparición de conceptos como alienación y falsa conciencia en Marx, autenticidad en Heidegger y mala fe en Sartre. En el mundo de la dignidad nos encontramos en una lucha entre la identidad subjetiva y la identificación mediante roles, ya que ahora las instituciones dejaron de ser la "casa del ser" para pasar a ser parte de las realidades opresivas que distorsionan y alejan al ser auténtico. De modo que será en los espacios vacíos de las instituciones donde el individuo esperará descubrirse, o al menos, definirse a sí mismo.

La presencia del concepto de honor en la conformación de la Argentina moderna 
El duelo por honor como práctica identitaria, colonial y excluyente en la Argentina moderna

Podemos comenzar este apartado realizando una reflexión acerca de los criterios de valoración culturales. En este sentido, Honneth comenta que "el autoentendimiento cultural de una sociedad proporciona los criterios según los que se orienta la valoración social de las personas" (Honneth, 1997, p.150). De manera que las capacidades y valores propios serán estimados intersubjetivamente (para bien o para mal) en tanto estas se encuentran en relación con valores socialmente definidos. Es esta forma de reconocimiento la que tiene sentido postular en nuestros modos de vida social cohesionados, en tanto que nos encontramos en una comunidad valorativa específica, la cual ha variado histórica y socialmente, orientada por ciertos objetivos comunes.

Basándonos en esta introducción podemos comenzar a entender que en el llamado período de "formación de la Argentina moderna" (desarrollado entre 18801920), era común encontrar que la exaltación del honor y el duelo eran considerados como naturales al considerarse estos como componentes esenciales de la cultura burguesa (Gayol, 2008, p.13). Como comenta la autora "el honor y especialmente el duelo hacían al "aire de familia" de las elites y formaban parte de su horizonte indispensable de referencias" (Gayol, 2008, p.13). No hay que dejar de resaltar que, a partir de 1880 Buenos Aires, ya la ciudad más importante y capital de la nación, se vio "afectada" por la inmigración masiva, de modo que "entre 1869 y 1914 la ciudad pasó de 180.000 a 1.500 .000 habitantes" (Gayol, 2008, p.15). Ante esta situación, es entendible que entre los habitantes de la elite se manifieste "la posibilidad de perderse en el conglomerado social y devenir un desconocido" (Gayol, 2008, p.15). De modo que se hizo necesario un mecanismo para imponerse ante el anonimato y así diferenciarse de los otros (además de para poder ganar respeto social y político), en una sociedad donde los marcos de referencia tradicionales, que previamente funcionaban como garantes de la posición social y como canales de acceso al poder político (en un mundo del honor, tal como fue previamente descrito), fueron sometidos a revisión, cuestionados y relativizados.

En este horizonte de referencias es que se entiende la inscripción e importancia de la retórica del honor y de la praxis del duelo. Además, es necesario tener en cuenta 


\section{Juan Ariel Paradela}

que a fines del siglo XIX "el honor masculino era muy diferente del honor feudal y también del honor más jerárquico del período colonial" (Gayol, 2008, p.18). Ya que, aunque tenía un andamiaje moral (propio de cualquier consideración de valor) este tenía poco que ver con el honor sexual, entendido como el control que los hombres ejercían hacia las mujeres para evitar el "deshonor sexual" y, al mismo tiempo, garantizar la fidelidad de la misma, lo cual era considerado como una virtud masculina y un atributo viril (Gayol. 2008, p.63) ${ }^{5}$.

Como la autora enfatiza en todo el libro, en el Buenos Aires de fin de siglo XIX, el honor ya no dependía del estatus heredado (el cual es propio del mundo del honor reflejado por Berger) sino de la percepción subjetiva y objetiva de la propia honorabilidad. Así es como la autora llega a definir este honor como un honor republicano, ya que este era (y aún es, como lo demuestran casos actuales ${ }^{6}$ ) un derecho que a priori tenían todos los ciudadanos ${ }^{7}$. $Y$ es un derecho que podemos ejercer porque este era y es un derecho constitucional garantizado por el estado y tipificado en el código penal ${ }^{8}$. Así, entendiendo el honor como uno de los referentes valorativos comunes y como una norma estable de conducta, al estar en parte asentado en las convicciones personales de los individuos, es como se pudo dar "una respuesta a la incertidumbre, a los rápidos cambios sociales y a la ampliación de la vida cívica que afectaban a los porteños" (Gayol, 2008, p.18).

Sobre la base de estas consideraciones podemos comprender la noción de honor como aquello que permite esencialmente una diferenciación, gracias a la caracterización de la identidad propia mediante relaciones intersubjetivas. En el marco

5 Según Gayol, Las mujeres estaban doblemente ausentes, ya que nunca aparecen como firmantes en los escritos y tampoco como objeto de las disputas masculinas $(2008$, p.46).

${ }^{6}$ Véase una noticia actual (2018) que refleja esto en: https://bit.ly/2ZvkzaL

${ }^{7}$ Hay que aclarar, como hace la autora, "que su práctica solo era posible entre quienes podían acceder al manejo de los símbolos y rituales que este implicaba" (Gayol, 2008, p.164). Por lo tanto, en la práctica, se excluía a la mayoría de la población.

${ }^{8}$ Como comenta Gayol: "Para el Código Penal que entró en vigencia en 1887, la injuria era una ofensa moral que atacaba el sentimiento subjetivo del honor y la calumnia, una valoración negativa- que otros hacían de la personalidad ético-social de un sujeto y que perjudicaba su fama" $(2008$, p.30). 
El duelo por honor como práctica identitaria, colonial y excluyente en la Argentina moderna

del contexto argentino, la identidad en la que permite inscribirse el duelo será específicamente en el universo de valores civilizatorios-europeos. Me interesa resaltar que esta inscripción en el universo de valores europeos se puede ver en tanto que la internalización del "código de honor" permitía la adopción de pautas de comportamiento asociadas con la civilidad y así la integración a un universo de caballeros internacionales. Es evidente, según la autora, que tanto la integración como la distinción "se fabricaron apelando a Europa como universo obligado de referencia" (Gayol, 2008, p.156). Esto se debe a que la elite argentina pretendía romper con su pasado vernáculo, de su propia su situación latinoamericana, y así insertarse "en un pasado occidental -honorable y aristocrático- [...] [y] en un presente civilizado y mundano, palpable en ciertos países europeos" (Gayol, 2008, p.173) ${ }^{9}$.

Aquí, frente a la necesidad de las élites de "crear valores de referencia comunes, conocidos y compartidos por todos para así construir la diferencia y la distancia social y política" (Gayol, 2008, p.16), es como la noción de honor y la práctica del duelo cobran su sentido. Así se entiende que la tesis central de la historiadora es que "el honor proveyó un lenguaje y un repertorio de valores indispensables en la dinámica social y política" (Gayol, 2008, p.16). Ya que, en un espacio social desordenado y en un espacio político que comienza a ser ampliado y altamente competitivo, la retórica del honor permitió crear un orden de referencias generales y mínimamente compartidas, y el duelo ${ }^{10}$ funcionó como un mecanismo de diferenciación social y política. Además, el duelo tuvo un rol clave en la construcción del gentleman debido a que considerarse uno de ellos no era meramente un atributo derivado de la posición social sino una condición lograda con esfuerzo. Esto puede verse reflejado en tanto que, en su expresión diaria, el caballero debía manifestar

${ }^{9}$ Esta inserción se llevaba a cabo en tanto que las elites estaban preocupadas y atentas a las novedades de los libros y objetos artísticos y costumbres de la cultura europea. De modo que "no escabapa a los caballeros argentinos que sus pares franceses y alemanes arreglaban sus diferencias apelando al duelo" (Gayol, 2008 p.173).

${ }^{10}$ Además del duelo, había distintos caminos para reparar el honor. En este sentido, la autora comenta que "los periódicos y la justicia pública, a través de las querellas por calumnias e injurias contempladas en el Código Penal, convivieron con un modo individual y físico de la defensa que encontró en el duelo su expresión más exquisita" (Gayol, 2008, p.103). 
ciertos hábitos que marquen su distinción como el "desterrar gestos de bravura, [o] alentar la pericia en el manejo del cuerpo" (Gayol, 2008, p.21). Estas virtudes, que eran asociadas con el código de honor, manifiestan la idea de que el duelo, el cual gozaba de un notable consenso público y estatal durante este período, debía ser pensado y presentado como una práctica promotora de la "civilización" ${ }^{11}$, ya que "un hombre honorable era, precisamente, aquel capaz de independizar o inmunizar sus comportamientos de cualquier forma de violencia" (Gayol, 2008, p.61) ${ }^{12}$.

Resulta muy interesante la comparación de la práctica del duelo entre caballeros con la práctica del duelo popular, el cual era asociado con los sectores populares. El segundo era estigmatizado por parte de la prensa y por los propios caballeros como un resabio bárbaro. Como antítesis del duelo entre caballeros, el cual definía estándares legítimos de conducta social y política, el duelo popular “experimentó un rápido proceso de criminalización y estigmatización" (Gayol, 2008, p.156) $)^{13}$. Gayol encuentra una nota de la prensa de 1880, titulada "pelea entre morenos" donde se relata la lucha entre dos sirvientes de casas de familia. Aquí se pone de relieve, que el cronista no retrata esta lucha como un duelo, sino que simplemente es una pelea sin sentido (Gayol, 2008, p.156-158). Esta estigmatización se debe en parte a que "los hombres de los sectores populares no eran vistos como poseedores de la necesaria racionalidad y autodisciplina como para batirse a duelo" (Gayol, 2008, pp.160-161). Como retomaremos más adelante con Quijano, aquí se pone de relieve la idea de duelo como estrategia de blanqueamiento.

\footnotetext{
${ }^{11}$ En este sentido, como aclara Gayol, "las expresiones de torpeza, la falta de sutileza y la inhabilidad corporal fueron esenciales como contracara de la definición del honor y devinieron una marca de incivilidad" (2008, p.69).

${ }^{12}$ Esta crítica a la violencia puede esclarecerse en tanto que en el recambio de siglo XIX al XX "la consolidación del estado central junto con el mayor control de las pasiones [...] evidentemente tuvieron consecuencias en las formas de agresión en general y en la legitimidad de las respuestas para defender el honor en particular" (Gayol, 2008, p.61).

${ }^{13}$ En este sentido, la autora comenta que en "el Código Penal de 1887 [...] se equipara al duelo popular con la figura jurídica de 'riña y/o lesiones' o de homicidio, y se le concede el carácter de 'delito especial o sui géneris'" (Gayol, 2008, p.161).
} 
El duelo por honor como práctica identitaria, colonial y excluyente en la Argentina moderna

Esta estigmatización del duelo de las clases populares tiene su paralelo literario en la figura del compadrito, el cual se convierte en el personaje central de un tipo especial de lírica en el tango en donde se propicia un modelo de masculinidad basado en la defensa del honor y el rechazo radical a la vergüenza (Archetti, 1998). Para precisar un poco más, se denominaba compadrito a un tipo social popular suburbano, aparecido en la segunda mitad del siglo XIX. En este sentido, compadrito se llamaba al joven de condición social modesta que habitaba en las orillas de la ciudad. Este es caracterizado en la lírica, según Archetti, como un "elegante seductor, irresistible para las mujeres y admirado por su coraje, fuerza física y capacidad de embaucar cuando la ocasión lo requiere" (Archetti, 1998, p.299).

Ahora bien, el duelo también implicaba una "nueva masculinidad", ya que el sujeto que se predisponía a batirse en duelo hacía gala "de una virilidad consciente de sí misma" (Gayol, 2008, p.22), en donde arriesgar la vida por el honor era entendido como un símbolo de prestigio, de certeza propia y también de masculinidad, en cuanto manifestación del coraje. En este sentido, podemos notar con Honneth que estos valores específicos, que eran considerados como honorables, no son sino "las interpretaciones culturales de los abstractos objetivos sociales, que se deben concretizar en cada caso en el mundo de la vida" (Honneth, 1997, p.156). Además, hay que notar que estas interpretaciones culturales son "determinadas por los intereses que los grupos sociales tienen en la valoración de las capacidades y cualidades que ellos representan" (Honneth, 1997, p.156). Por eso, el que duela ${ }^{14}$, si es que es un sujeto perteneciente a un cierto sector social privilegiado, aporta al desarrollo y concretización de los valores sociales establecidos, y de esta manera se autorrealiza socialmente sobre la base de los valores determinados por el grupo social en el cual pretende inscribirse.

Como ya se ha comentado, el honor era una cualidad individual, pero que se pone en juego en el plano social, en tanto que el manifestar en público la intención de

\footnotetext{
${ }^{14}$ Una característica importante del duelo es que, entre otros requisitos y reglas, era necesaria "la igualdad de condición reconocida entre los adversarios" (Gayol, 2008, p.113).
} 


\section{Juan Ariel Paradela}

defender el honor era un camino necesario para la construcción de la respetabilidad pública. Esto se entendía así, ya que el honor era una virtud básica "que habilitaba a competir por un puesto en general o por un cargo político en particular" (Gayol, 2008, p.44) ${ }^{15}$. Esta habilitación a la competencia por un cargo político, en este contexto histórico, se puede entender en tanto que el sistema político donde se asentaba priorizaba las lealtades personales y la personalidad de los dirigentes más que las plataformas de los partidos (Gayol, 2008, p.83). Además de habilitar a un cargo político, debía defenderse el honor ante acusaciones de corrupción o de robo, que desacreditaban a la persona y la exponían como carente de respeto. Es interesante señalar que el poner la riqueza o la propiedad en el centro de la escena de las acusaciones, cobran sentido en un contexto de capitalismo pujante y de crecimiento económico. Allí estos "valores del capitalismo" vienen a reemplazar la preponderancia de "valores esencialmente físicos y morales validados en sociedades más inestables [...] y desorganizadas" (Gayol, 2008, p.67). Sin embargo, no hay que dejar de marcar que la acusación de cobarde nos hace captar la dimensión física del honor, en tanto que esta imputación "le negaba al destinatario el valor indispensable y necesario para afrontar el peligro físico o intelectual [...] [en el] defender con ahínco y convicción sus ideas en una discusión" (Gayol, 2008, p.70).

Gayol encuentra que las nociones jerárquicas del honor, que manifestaban la importancia de la sangre, el linaje y la antigüedad familiar como generadores de estatus y privilegio, fueron efectivamente reemplazadas en el curso del siglo XIX, por el énfasis en un lenguaje más universal e igualitario. Así es que la autora afirma que el estatus fue cediendo paso a la virtud y al desarrollo de "un sentido del honor más igualitario y republicano -asentado básicamente en el trabajo regular, la honradez, el coraje, el interés y la participación en la vida pública-" (Gayol, 2008, p.94) el cual constituyó la base necesaria para la definición de los derechos y las obligaciones de la ciudadanía, como se expresa, en parte, en el ejercicio del voto masculino.

\footnotetext{
${ }^{15}$ Además, “los dirigentes 'crecidos al calor de la acción' necesitaban del honor para ganar prominencia [pública]" (Gayol, 2008, p.95).
} 
El duelo por honor como práctica identitaria, colonial y excluyente en la Argentina moderna

Esta caracterización del honor que Gayol expresa es posible contrastarla con la que nos encontrábamos en Berger. En efecto, aquí se ve que el honor republicano no es exactamente el honor colonial pre-moderno descrito por Berger, ya que es posible encontrarlo en las legislaciones modernas y porque tiene un alcance más amplio al que este le adjudicaba. Además, el honor republicano tiene atribuciones diferentes a la que se ha detallado con Hegel. En específico, se traza el honor no solo como la identificación de las cualidades propias sino también como una norma de conducta que regía para cierta clase social.

Para finalizar esta sección, es preciso comentar brevemente lo que la historiadora describe como el ocaso de la práctica (y de la utilidad) del duelo. La autora comenta que es en la segunda década del siglo XX donde el duelo entre caballeros comienza a perder visibilidad y aceptación social. Una de las causas de este declive, que producían que el duelo sea visto como un simulacro totalmente anacrónico, es atribuido a la situación internacional luego de la Primera Guerra Mundial. En este sentido, Gayol comenta que era cuestionada la autoridad con la que los duelistas podían invocar la violencia ante el horror que visto en los campos de batalla, y más aún, era criticado el supuesto coraje que estos pregonaban en los duelos, ya que "las hazañas y el heroísmo que se ponían en juego en el curso de largas batallas era poco comparable con el gesto supuestamente heroico de erigirse en duelista y mirar a su oponente a los ojos" (Gayol, 2008, p. 226). Otra de las consecuencias que se puede atribuir a la situación Primera Guerra Mundial es que el "horror de las trincheras quitó al duelo la pretensión de ser el único rito viril por el cual el hombre moderno podía hacer frente a la muerte y medir el coraje frente a sus pares" (Gayol, 2008, p.227). Si bien esto la autora observa que es aplicable en los casos de Alemania y Francia, es posible encontrar que estas transformaciones fueron recibidas por la elite porteña, en tanto que se creó la primera liga porteña antiduelo apenas terminada dicha guerra. Estas transformaciones y este clima anti-duelo generaron que el honor deviniera "una noción que remitía fundamentalmente a la honradez, al comportamiento correcto y al buen desempeño profesional de un hombre" (Gayol, 2008, p.229). Estas cualidades más personales del honor, que fueron consagradas adentrado el siglo XX, expresan una 


\section{Juan Ariel Paradela}

primacía del honor "interno" por sobre el "externo", movimiento que convierte al honor en un asunto más de autoconciencia y autocontrol que de prestigio y reputación.

Este cambio esencial de la concepción del concepto de honor también es verificable vía el rol que cumplió la escuela pública. Como comenta la historiadora, la escuela pública no sentó sus bases sobre la personalidad y la originalidad, sino que resaltó la importancia de la cuestión y unidad nacional. De manera que los contenidos nacionales de los nuevos planes y programas resaltaban la importancia concedida a "la enseñanza de la historia patria y a la realización de actos escolares [que] hacía que los 'buenos e inteligentes ciudadanos' se nutrieran de un sentido comunitario y de conformismo social, y no que exaltaran su personalidad e individualidad" (Gayol, 2008, p.234). Es notorio entonces que las prácticas desplegadas por la escuela para inculcar la nacionalidad contrastaban con el duelo. Así, la nueva defensa del honor no se refería al honor particular, sino que remitía a lo colectivo en un sentido más amplio, esto es, a defender el honor de la república cumpliendo con la ley. De modo que así se entiende que la educación, junto con los deportes ${ }^{16}$, cumplieron un papel decisivo en el cambio de actitud de las elites en relación con el duelo (Gayol, 2008, p.235).

Así podemos comprender que el mundo de la dignidad, tal como fue desarrollado con Berger, encontró un lugar preponderante en la elite porteña luego de la Primera Guerra Mundial y fue asentado tanto por la conciencia de lo ocurrido en aquella guerra, como por el rol que cumplieron la escuela pública y la irrupción de los deportes como proveedores de nuevos valores vinculados con los cambios ocurridos en la sociedad. Así, "los cambios políticos, sociales y culturales privaron al honor y al duelo de su base cultural y le quitaron así el rol crucial que había desempeñado en la

\footnotetext{
${ }^{16}$ La influencia de los deportes respecto del cambio de actitud de las élites frente al duelo puede entenderse en tanto que estos acarreaban valores muy diferentes a los del duelo. Específicamente, mientras los duelistas tenían como objetivo demostrar el coraje en la predisposición a batirse en duelo, en el deporte se entraba en competición con otros e importaba el rendimiento, medible en obtener la victoria o caer derrotado. En este sentido, los deportes (como el polo, el fútbol y el boxeo) "estaban mucho mejor equipados para proveer sensaciones y experiencias vinculadas con el cambio, la velocidad y la experimentación" (Gayol, 2008, p.235).
} 
El duelo por honor como práctica identitaria, colonial y excluyente en la Argentina moderna

construcción de la distinción y del ordenamiento [...] para la cual habían sido convocados en la Argentina moderna" (Gayol, 2008, p.237).

\section{La categoría de raza como fundamento de la exclusión del duelo}

Considero que el análisis de Gayol nos permite reflexionar acerca de los motivos de por qué había ciertos hombres que podían batirse a duelos (los propietarios, los que tenían y disponían de capital social para poder llevar a cabo el rito del duelo), y ciertos hombres que no, los varones de sectores populares. En este sentido, considero que debemos ahondar en los significados que implica aquella exclusión. Por lo tanto, me parece necesario comprender la construcción discursiva de estos otros tomando como base la idea de raza de Aníbal Quijano, ya que nos permitirá establecer una posible fundamentación de aquella exclusión.

En efecto, es precisamente la constitución de América (su conquista) y el surgimiento del capitalismo colonial/moderno y eurocentrado lo que para él genera un nuevo patrón de poder mundial. De aquí que la idea de raza haya sido uno de los elementos que funda el nuevo patrón de poder mundial, ya que permite la clasificación social universal del planeta. De este modo, pensar la idea de raza en el fundamento del orden social colonial, implica entender que, desde una supuesta diferencia estructural biológica, se codificaron las diferencias entre conquistadores y conquistados, ubicando "a los unos en situación natural de inferioridad respecto de los otros" (Quijano, 2000, p.202). La categoría de raza, según Quijano, "en su sentido moderno, no tiene historia antes de América" (2000, p.202) y, como tal, generó identidades sociales nuevas: indios, negros y mestizos. Específicamente en América, "la idea de raza fue un modo de otorgar legitimidad a las relaciones de dominación impuestas por la conquista" (Quijano, 2000, p.203).

Esta legitimación de las relaciones de dominación produce luego una epistemología (elaboración de la perspectiva eurocéntrica del conocimiento) y una 
naturalización de las "relaciones coloniales de dominación entre europeos y no europeos" (Quijano, 2000, p.203). Asimismo, como dice Quijano, “Europa también concentró bajo su hegemonía el control de todas las formas de control de la subjetividad, de la cultura y en especial del conocimiento, de la producción del conocimiento" (2000, p.209). Así, mediante la ruptura de los patrones de producción de sentido autóctonos y el forzar a los colonizados a aprender la cultura de los conquistadores, se impuso el "eurocentrismo como el nuevo modo de producción y de control de la subjetividad" (Quijano, 2014, p.637).

Además, debemos notar que la imposición de la cultura del colonizador realiza una construcción identitaria sobre el colonizado. En este sentido, Bhabha "piensa el discurso colonial con un efecto de intencionalidad de construir al colonizado como una población "degenerada" o "inferior" a causa de su origen racial [...] para justificar así su conquista y establecer sistemas para su administración e instrucción" (Bidaseca, 2010, p.37). Esta construcción no es algo fácil de quitarnos de encima, ya que aun actualmente, como dice Said, pervive por fuera del poder visible, en tanto que "La experiencia de ser colonizados, [...] subalternos y sometidos a Occidente no terminó para parafrasear a Fanon- cuando el último policía blanco fue licenciado y la última bandera europea cayó" (Said, 1996, citado en Bidaseca, 2010 p.82). En este sentido, como afirma Castro-Gómez, "La colonialidad del poder se revela, entonces, como un deseo por identificarse con el conquistador europeo, esto es, de verse y definirse a sí mismos a partir del espejo del colonizador" (2014, p.83).

A raíz de lo dicho, comprendemos que es por los condicionamientos históricos y sociales que ha impuesto la colonización y la racialización de la población, que el duelo fue utilizado como un método que permitió eficazmente diferenciar a la élite de los sectores de las clases populares, cuyos enfrentamientos eran reducidos y comprendidos por las elites como mera violencia sin sentido. Por lo tanto, es posible inscribir el duelo en lo que Castro-Gómez establece como una estrategia para el blanqueamiento, como un diferenciador que permitía trazar la frontera entre blancos y no-blancos (2014, p.85). En este sentido, el duelo sería una de las tantas técnicas, 
El duelo por honor como práctica identitaria, colonial y excluyente en la Argentina moderna

como el ingreso a la educación universitaria en la época colonial, mediante el cual la colonialidad del poder se pone en práctica.

\section{Conclusiones}

A partir de lo desarrollado considero que es posible señalar que el honor, dentro de la problemática del reconocimiento hegeliano, expresa que existen diversas instituciones que acompañan el desarrollo ético-individual, y que son parte ineludible de cualquier desarrollo humano. Así encontramos que el sistema hegeliano de reconocimiento implica simultáneamente el desarrollo de una teoría de las instituciones (como el derecho), las cuales son condiciones fundamentales para la formación de los distintos estadios de la eticidad. Por lo tanto, es posible problematizar la transición del "mundo de honor" al "mundo de la dignidad" hecha por Berger, ya que es posible pensar, apoyándonos en Hegel, que en el mundo de la dignidad también hay una pervivencia (aunque menor) de un vínculo entre la identidad propia con los roles institucionales establecidos en la sociedad, en tanto que las instituciones, entendidas a raíz de las transformaciones políticas, sociales y culturales, pueden dar lugar a relaciones de reconocimiento tanto acordes a propiciar la integridad de uno como persona digna y reconocida, como de relaciones de reconocimiento falsas, tal como se puede encontrar en los países que no reconocen en sus sistemas de derecho a la identidad transgénero como válida, imponiendo el reconocimiento formal de uno mismo únicamente como "varón" o "mujer".

Del análisis realizado del libro de Sandra Gayol me interesa resaltar el valor que tiene el honor en la conformación de las subjetividades en pleno recambio de siglo. En este sentido, en un contexto de gran crecimiento económico, poblacional, y de cambios culturales profundos, la defensa del honor, expresado en la práctica del 


\section{Juan Ariel Paradela}

duelo $^{17}$, funcionó como diferenciador social de una élite en plena recomposición y como medio legítimo para la defensa de la reputación de la clase política y dirigente. La relación del honor, como es entendido aquí, puede vincularse con el desarrollo de Hegel en tanto que "la predisposición a arriesgar la vida pasó a ser mucho más importante que la posible victoria, y el gesto de coraje [...] más significativo que la necesidad de demostrarlo en actos concretos" (Gayol, 2008, p.73). De modo que lo que encontramos es una noción de honor, que se expresa en la predisposición a arriesgar la vida en una lucha, la cual es necesaria llevar a cabo para permitir reconocernos como hombres verdaderamente humanos. Lo que agregaría Gayol a los desarrollos hegelianos es que este reconocimiento de ser un ser humano digno está inscripto en un universo de valores específicamente civilizatorios-europeos, en tanto que los duelistas, defendiendo el honor, se inscribían en una comunidad internacional de caballeros.

Por último, cabe comentar que el aporte de Aníbal Quijano y su fundamentación de la exclusión del otro, basada en la categoría de raza, nos ha permitido problematizar la inscripción y la asignación valorativa que implicaba el honor en las elites. En efecto, junto con Castro-Gómez, nos permite ver el duelo como una estrategia de blanqueamiento y diferenciación de la élite con respecto a las clases populares. De esta manera la colonialidad del poder se pone en práctica y opera como una técnica que racializa los cuerpos y les asigna un lugar en la sociedad.

\section{Referencias Bibliográficas:}

\footnotetext{
${ }^{17}$ Esta práctica, como comenta Gayol, "se convirtió en el símbolo quizás más importante de diferenciación entre los hombres superiores y los hombres inferiores de la sociedad" (2008, p.138). Esto se debe al arco de posibilidades que el duelo aportaba, en tanto que este "no solo era un acto que suprimía la causa del escándalo y restauraba el honor herido, sino que hacía de puente entre dos caballeros y creaba lazos más allá de las diferencias de fortuna [...] y de posición" (Gayol, 2008, p.163).
} 
El duelo por honor como práctica identitaria, colonial y excluyente en la Argentina moderna

- Abril, F. (2012) "Sobre el delito. La lectura de Axel Honneth del Sistema de Eticidad de Hegel" en Nuevo Itinerario Revista Digital de Filosofía, Vol 7, Número VII, Resistencia, Chaco, Argentina.

- Archetti, E. (1998) “Masculinidades múltiples. El mundo del tango y del fútbol en la Argentina", en Balderston, D. y Guy, D. (eds.) Sexo y Sexualidades en América Latina, Buenos Aires: Paidos, pp. 291-312.

- Berger, P. (1983) "On the obsolescence of the Concept of Honor" en Revisions: Changing Perspectives in Moral Philosophy, Hauerwas, S., Maclntyre, A. (eds) Notre Dame (Indiana), Notre Dame University Press, pp. 172-181. [Traducción propia].

- Bidaseca, K. (2010) Perturbando el texto colonial. Los Estudios (Pos)coloniales en América Latina, Bs. As, Ed. SB.

- Campbell, J. K. (1964), Honour, Family and Patronage, New York, Oxford University Press.

- Castro-Gomez, S. (2014) “Cuerpos racializados. Para una genealogía de la colonialidad del poder en Colombia" en Cardona Rodas, H.; Pedraza Gómez, Z (Comps.) Al otro lado del cuerpo. Estudios biopolíticos en América Latina. Bogotá: Universidad de los Andes-Universidad de Medellín.

- Cervantes, M. (1922) Don Quijote de la mancha, Madrid, Instituto-Escuela.

- Elias, N. (1993) La sociedad cortesana, Madrid, FCE.

- Gayol, S. (2008) Honor y duelo en la Argentina moderna, Buenos Aires, Siglo XXI,

- Hegel, G. W. (2006) El sistema de la eticidad, Buenos Aires, Quadrata

- Hobbes, T. (2007) Leviatan, Buenos Aires, Losada.

- Honneth, A. (1997) La lucha por el reconocimiento, Barcelona, Crítica.

- De La Maza, L. M. (2010) "Actualizaciones del concepto hegeliano de reconocimiento" en Veritas, N.․, 23, pp. 67-94. ISSN 0717-4675. 
- Quijano, A. (2000) "Colonialidad del poder, eurocentrismo y América Latina" en Lander (comp.) La colonialidad del saber: eurocentrismo y ciencias sociales. Perspectivas latinoamericanas, Buenos Aires, CLACSO.

- Quijano, A. (2014) Cuestiones y horizontes, Buenos Aires, Ed. CLACSO.

- Rendón, C. (2010) La lucha por el reconocimiento en Hegel. Génesis y significado, Antioquía, Universidad de Antioquía.

- Said, E. (1996) Cultura e Imperialismo, Barcelona, Anagrama.

- Soriano, F. (2018) "En un fallo inédito, la Justicia argentina condena a una tuitera por calumnias e injurias" en Infobae [online]. Disponible en: https://bit.ly/2ZvkzaL. Visto el 20/02/2021.

- Prada Londoño, M.A. (2015) "la idea de reconocimiento en el Hegel de Jena. Una lectura con Paul Ricoeur" en Franciscanum 163, Vol. LVII, pp.21-49. 